\title{
Sistema radicular dos citros em Neossolo Quartzarênico dos Tabuleiros Costeiros sob irrigação e sequeiro
}

\author{
Laercio Duarte Souza(1), Luciano da Silva Souza ${ }^{(1)}$ e Carlos Alberto da Silva Ledo(1)
}

\author{
(1)Embrapa Mandioca e Fruticultura, Caixa Postal 007, CEP 44380-000 Cruz das Almas, BA. E-mail: laercio@cnpmf.embrapa.br, \\ Isouza@cnpmf.embrapa.br, ledo@cnpmf.embrapa.br
}

\begin{abstract}
Resumo - O objetivo deste trabalho foi avaliar o sistema radicular da laranjeira 'Pêra' Citrus sinensis (L.) Osb., enxertada em limoeiro 'Rugoso' Citrus jambhiri Lush., plantada no espaçamento 6x4 m, sob sistema irrigado com microaspersores e sob sequeiro. O solo da área experimental, localizada em Itapicuru, BA, é um Neossolo Quartzarênico, com horizonte subsuperficial coeso. O delineamento experimental foi o inteiramente casualizado, e foram avaliadas cinco plantas em cada sistema. Amostras de raiz foram coletadas a cada 0,5 m de distância do caule, em seis profundidades, em quatro locais, na linha de plantas e seis nas entrelinhas. A distribuição das raízes foi avaliada em três classes de diâmetro $(<0,5 ; 0,5-1$ e $>1 \mathrm{~mm})$. A comparação entre os locais, em relação à planta, nos sistemas irrigado e sequeiro, tanto na linha de plantas quanto na entrelinha, apresentou diferenças na distribuição de raízes apenas à profundidade de 0-0,20 m. As 36 combinações dos três diâmetros de raiz e das seis profundidades, entre os sistemas irrigado e sequeiro, mostraram diferenças na distribuição de raízes apenas no diâmetro $<0,50 \mathrm{~mm}$, na linha de plantas, à profundidade de $0-0,20 \mathrm{~m}$, e no diâmetro $>0,5 \mathrm{e}<1 \mathrm{~mm}$, na entrelinha, à profundidade de $0,40-0,60 \mathrm{~m}$.
\end{abstract}

Termos para indexação: Citrus sinensis, Citrus jambhiri, solos coesos, raiz.

\section{Citrus root system in Coastal Tablelands on Typic Quartzipsamment under irrigation and rainfed conditions}

\begin{abstract}
The aim of this work was to evaluate the root system of 'Pera' orange tree Citrus sinensis (L.) Osb. grafted on 'Rugoso' lemon tree Citrus jambhiri Lush., cultivated with spacing within and between rows of 4 and $6 \mathrm{~m}$, respectively, under rainfed conditions and under irrigation. The experimental area was established in Itapicuru, BA, Brazil, in a Typic Quartzipsamment soil with a subsuperficial cohesive layer. The experimental was a completely randomized design with five plants evaluated at each system. Root samples were collected in six positions between rows and four positions within rows, spaced of $0.5 \mathrm{~m}$ from tree's stem. At each position, the roots were sampled in six depths. Root distribution was evaluated using three ranges of root diameters $(<0.5 ; 0.5-1$ and $>1 \mathrm{~mm}$ ). Comparing the positions from the plants, within and between rows in both systems, the root distribution was different only at depth $0-0.20 \mathrm{~m}$. Comparing the two systems, among the 36 combination of 6 depths $x 3$ root diameters $x 2$ water status, the root distribution was different in two cases: the diameter $<0.5 \mathrm{~mm}$, within planting rows at $0-0.20 \mathrm{~m}$ and the diameter $>0.5$ and $<1 \mathrm{~mm}$, between rows at $0.40-0.60 \mathrm{~m}$.
\end{abstract}

Index terms: Citrus sinensis, Citrus jambhiri, cohesives soils, root.

\section{Introdução}

O Brasil é o maior produtor mundial de citros e colheu, no ano de 2005, em uma área de 916.931 ha, um total de $20.116 .573 \mathrm{t}$ de frutas. O cultivo de laranja ocupou $87,87 \%$ da área plantada e respondeu por $88,75 \%$ dessa produção. Em relação aos pomares de laranja, os estados de São Paulo, Bahia e Sergipe possuem 71,31, 6,28 e $6,79 \%$ da área plantada e responderam por $80,49,4,49$ e $4,14 \%$ da produção, respectivamente o primeiro, o segundo e o terceiro produtor de laranja do País, com produtividade de 25, 16 e $14 \mathrm{t} \mathrm{ha}^{-1}$ por ano (IBGE, 2007).

A citricultura tropical litorânea, estabelecida nos estados da Bahia e Sergipe, localiza-se nos Tabuleiros Costeiros, que são platôs litorâneos relacionados aos sedimentos da Formação Barreiras, que vão desde o Estado do Rio de Janeiro até o Amapá, e apresentam solos onde predominam horizontes subsuperficiais coesos (Jacomine et al., 1977). A presença dos solos coesos e a distribuição irregular de chuvas (70 a $80 \%$ 
concentradas entre abril a setembro) são as maiores limitações à produção nesses pomares. A formação do horizonte coeso é atribuída à gênese desses solos e ocorre entre 0,30 e 0,70 $\mathrm{m}$ de profundidade (Jacomine, 2001). A resistência à penetração aumenta de forma exponencial com a redução da umidade do solo, nos horizontes coesos dos Tabuleiros Costeiros, e de forma linear nos não coesos (Giarola et al., 2001). A baixa saturação por bases e a alta acidez ativa e trocável, a partir da profundidade de $0,20 \mathrm{~m}$ nos solos onde estão esses pomares (Coelho et al., 1993), também são inibidores do desenvolvimento das raízes.

Nesses solos, o desenvolvimento radicular em profundidade é mínimo, pois as raízes tendem a se desenvolver apenas nas fraturas existentes nas camadas coesas; além disso, ocorre redução no volume dessas raízes, em relação aos horizontes sobre e subjacentes (Demattê et al., 1996). No caso dos citros, cerca de 60\% de seu sistema radicular está na profundidade de $0-0,20 \mathrm{~m}$, e $90 \%$ entre 0 e 0,40 m (Cintra et al., 1999; Souza et al., 2004b). A roçagem na época das chuvas e a gradagem no período seco na entrelinha, em conjunto com outras práticas mecânicas utilizadas na citricultura, tendem a compactar o solo na profundidade $0-0,10 \mathrm{~m}$ (Portela et al., 2001) o que, em interação com a coesão subsuperficial oriunda da gênese desses solos, restringe a infiltração e aumenta a perda de água por evaporação (Paiva et al., 1998; Souza \& Paiva, 2001). Essa situação faz com que o maior volume de água nesses solos, ao longo do ano, esteja disponível às plantas a partir de 0,90 $\mathrm{m}$ de profundidade (Souza et al., 2004a), ocorrendo deficiências hídricas por 10 a 20 semanas em profundidades de até 1,50 m (Paiva et al.,1998).

A camada coesa, quando úmida, permite a penetração das raízes e maior movimentação da água no perfil do solo, o que faz da irrigação uma das tecnologias mais difundidas como solução para os solos coesos. No entanto, os rios não correm ao longo dos Tabuleiros Costeiros, apenas o atravessam quando chegam ao seu delta, o que torna pontual a disponibilidade de água para irrigação. As alternativas são práticas culturais como: a manutenção de coberturas vegetais no solo e a subsolagem profunda (Carvalho et al., 1999; Rezende et al., 2002; Souza et al., 2004a); a cova de plantio com profundidade maior do que a camada coesa (Souza et al., 2004); o uso de calcário e gesso, para aumentar a saturação por bases em profundidade maior do que 0,40 m (Rezende et al., 2002); e o uso de porta-enxertos, com capacidade de explorar maior volume de solo em profundidade (Cintra et al., 1999; Neves et al., 2004). A utilização dessas práticas, de forma interativa, tem aumentado a produtividade desses pomares. No entanto, apesar da escassez de água para a irrigação nos Tabuleiros Costeiros, esta prática continua sendo almejada na expectativa de não apenas suprir a necessidade de água, mas também para melhorar a morfologia da planta, pois, se os horizontes coesos não apresentam resistência quando úmidos, as plantas irrigadas podem desenvolver um sistema radicular mais profundo e estar, portanto, mais aptas a explorar maior volume de solo e água no solo, mesmo que posteriormente sejam submetidas à condição sem irrigação.

O objetivo deste trabalho foi dimensionar a capacidade de explorar o solo das raízes de plantas de laranjeira 'Pêra', enxertadas sobre limoeiro 'Rugoso', estabelecidas em solo coeso dos Tabuleiros Costeiros, comparando pomares submetidas a sistemas de produção com e sem irrigação.

\section{Material e Métodos}

O trabalho foi desenvolvido em 2004, na fazenda Alto da Capoeira, no Município de Itapicuru, BA, a $11^{\circ} 19^{\prime} 1$ "S e $38^{\circ} 13^{\prime} 58^{\prime \prime} \mathrm{W}$, onde o clima é do tipo As, conforme classificação de Köppen.

O pomar de laranjeira 'Pera' Citrus sinensis (L.) Osb., enxertada em limoeiro 'Rugoso' Citrus jambhiri Lush., foi instalado em 1990, no espaçamento de 6x4 m. A área plantada foi de $60 \mathrm{ha}$, dos quais 30 ha irrigados desde a fase de plantio, com microaspersores localizados na linha de plantas, a $2 \mathrm{~m}$ de cada planta, com vazão de $80 \mathrm{~L} \mathrm{~h}^{-1}$, e turno de rega de 24 horas no período seco (outubro a março). Os demais 30 ha, em área contínua, foram mantidos sem irrigação. O declive da área amostrada é menor do que 3\%. As práticas culturais utilizadas no pomar foram: roçadeira na entrelinha, no período de chuvas, e grade no período seco. $\mathrm{Na}$ linha de plantas, o controle do mato foi realizado com capina manual e herbicida. A adubação obedeceu às recomendações das análises do solo e foi realizada na linha de plantas.

A amostragem do solo para as análises físicas foi realizada em trincheiras, com dimensões de $1 \mathrm{x} 1,5 \mathrm{~m}$ e profundidade de $1,80 \mathrm{~m}$, abertas em posição perpendicular às linhas, em ponto eqüidistante das plantas, tendo sido duas na área sob irrigação e duas sob sequeiro, que formaram um quadrado com cerca de $150 \mathrm{~m}$ de 
distância entre uma trincheira e outra. Foram avaliadas as profundidades: $0-0,30 \mathrm{~m}$, zona de ação das práticas culturais; $0,30-0,55 \mathrm{~m}$, zona mais coesa do solo; 0,55-1,05 m, zona alcançada pelo molhamento; 1,05-1,25 m, zona de alcance das raízes. A amostragem para as análises químicas foi realizada nas profundidades de $0-0,20$ e $0,20-0,40 \mathrm{~m}$, para linha de plantas e entrelinha, no sistema de amostras compostas com oito subamostras. As análises físicas e químicas do solo foram realizadas nos laboratórios da Embrapa Mandioca e Fruticultura Tropical, segundo a metodologia de Embrapa (1997). O solo foi classificado como Neossolo Quartzarênico distrófico (Embrapa, 1999).

A avaliação das raízes foi realizada em cinco plantas, em cada sistema. A partir da interface das áreas sob sequeiro e irrigada, foram numeradas dez linhas de plantas para cada lado, tendo-se eliminado as cinco primeiras e sorteado as linhas de seis a dez. Dentro de cada linha, foram sorteadas plantas numeradas de 1 a 100 . Como o espaçamento do pomar era $6 \times 4 \mathrm{~m}$, as amostras das raízes de cada planta foram retiradas até a distância de $3 \times 2 \mathrm{~m}$, na entrelinha e linha de plantas, respectivamente, em eixos perpendiculares, onde a planta é o ponto de intersecção. Os pontos de amostragem, distanciados $0,5 \mathrm{~m}$ um do outro, totalizaram seis locais na entrelinha e quatro na linha de plantas. As profundidades amostradas foram: $0-0,20,0,20-0,40$, $0,40-0,60,0,60-0,80,0,80-1,00$ e $1,00-1,20 \mathrm{~m}$. A coleta foi realizada com um cilindro de aço, de $1,35 \mathrm{~m}$ de comprimento e diâmetro de $0,10 \mathrm{~m}$, com a umidade no solo próxima à da capacidade de campo, tendo-se retirado $0,20 \mathrm{~m}$ de cada vez, em cada local, até a profundidade de $1,20 \mathrm{~m}$.

As raízes foram separadas do solo por imersão em água, peneiramento e secagem à sombra. As amostras foram digitalizadas em escaner e processadas pelo programa GSRoot (Guddanti \& Chambers, 1993), que subdividiu o diâmetro das raízes em três classes: $\mathrm{D} 1<0,5$; $0,5<\mathrm{D} 2<1 ; \mathrm{D} 3>1 \mathrm{~mm}$, e determinou o somatório do comprimento das raízes, em cada diâmetro.

A análise da variância foi realizada em delineamento inteiramente casualizado no esquema de parcela subsubdividida no espaço, tendo-se individualizado os locais da linha de plantas e entrelinhas. Para a linha de plantas, utilizou-se o esquema $2 \times 4 \times 6 \times 3$, para dois sistemas de produção, quatro posições em relação à planta, seis profundidades e três diâmetros de raiz, com cinco repetições (plantas). Para as entrelinhas, foi utilizado o esquema $2 \times 6 \times 6 \times 3$, com seis posições em relação à planta na entrelinha, e os demais termos definidos como anteriormente. Os três diâmetros de raiz foram comparados nos dois sistemas de produção, em relação às seis profundidades, num total de 36 contrastes. Os locais em relação à planta foram comparados entre si, em cada uma das 36 situações. Também foram determinados os valores porcentuais relativos das raízes, dentro de cada variável. A parcela experimental foi constituída de uma amostra de raiz de determinado diâmetro, retirada em cada profundidade, posição em relação à planta e sistema de produção. As médias dos tratamentos foram comparadas pelo teste de Tukey, a 5\% de probabilidade. As análises estatísticas foram realizadas pelo SAS (SAS Institute, 1999).

\section{Resultados e Discussão}

Os resultados das análises do solo (Tabelas 1, 2 e 3) representam as médias das áreas sob irrigação e sob sequeiro. A opção em apresentar as médias deveu-se ao fato de que a comparação entre os parâmetros físicos destas áreas, pelo coeficiente de correlação de Pearson, apresentou os valores: $0,99 * * ; 0,99 * * ; 0,98 * *$ e $0,98 * *$, para as profundidades de $0-0,30,0,30-0,55,0,55-1,05$ e 1,05-1,55 m, respectivamente. Os parâmetros químicos apresentaram coeficiente de correlação no valor de $0,94^{* *}$. Essa similaridade deve ser atribuída à gênese do solo, às práticas mecânicas, à adubação e à correção do solo, que foram iguais nos dois sistemas.

A granulometria mostrou um teor de argila menor do que $150 \mathrm{~g} \mathrm{~kg}^{-1}$, em todo o perfil, enquanto a areia total variou de $889 \mathrm{~g} \mathrm{~kg}^{-1}$ na camada superficial, a $788 \mathrm{~g} \mathrm{~kg}^{-1}$ na profundidade de 1,05-1,50+ $\mathrm{m}$, o que indica um solo com alta porosidade e boa drenagem (Tabela 1). No entanto, houve predomínio da areia média e da areia fina, cerca de $75 \%$ da areia total, que são frações que tendem a favorecer ao arranjo de partículas bastante próximas e adensadas (Resende et al., 1992). A avaliação de oito perfis de solos dos Tabuleiros Costeiros mostrou que a fração areia influenciou no aumento da compactação nos horizontes com maior resistência à penetração (Abrahão et al., 1998). Horizontes coesos em solos arenosos também foram registrados por Lima et al. (2004) em Tabuleiros Costeiros no Estado do Ceará.

A zona caracterizada como coesa, nesse solo, foi na profundidade de $0,30-0,55 \mathrm{~m}$, que nas avaliações em campo, além da extrema dureza quando seca, apresentou uma visível descontinuidade em relação à presença de 
raízes, o que é considerado um eficiente indicador para se avaliar a coesão em campo (Santana et al., 2006). Nas análises físicas, essa camada apresentou o menor volume de macroporos, o maior valor para a densidade do solo, condutividade hidráulica saturada duas a três vezes menor do que nas demais camadas, baixo teor de água disponível às plantas, e a menor umidade, em todo o perfil, para os potenciais matriciais avaliados (Tabelas 1 e 2).

Nas análises químicas, observou-se que na profundidade de $0-0,20 \mathrm{~m}$, na linha de plantas, a saturação por bases esteve próxima de $60 \%$, e o pH próximo de 6, valores recomendados pelo Grupo Paulista de Adubação e Calagem para Citros (1994). $\mathrm{Na}$ entrelinha, o valor do $\mathrm{pH}$ foi 5,2 e $\mathrm{V}$ não chegou a $50 \%$. A CTC foi muito baixa, na linha e entrelinha, em função do alto teor de areia e baixa porcentagem de matéria orgânica. Na profundidade de $0,20-0,40$ m, o alumínio aumentou, enquanto $\mathrm{V}$, pH e matéria orgânica diminuíram (Tabela 3). Esses resultados são parcialmente explicados pelo sistema de adubação (superficial e ao redor da copa) e correção (doses de calcário que corrigem apenas a profundidade de $0-0,20 \mathrm{~m}$ ) utilizados nesses pomares, que aumentaram o teor de nutrientes apenas na linha de plantas e próximo à superfície (Coelho et al., 1993), tendo-se constituído em mais um fator para aumentar a concentração de raízes nessa zona do solo.

Nas Figuras de 1 a 6 , estão os dados referentes à distribuição de raízes. Nas Figuras 1 e 2 estão os resultados para o diâmetro D1 $(<0,5 \mathrm{~mm})$, que representa $44 \%$ do sistema radicular das plantas avaliadas. Na linha de plantio, dentro de cada sistema, houve diferenças entre as posições de amostragem, apenas na profundidade de $0-0,20 \mathrm{~m}$, onde a densidade de raízes diminuiu, à medida que se afastou da planta, não tendo havido diferenças nas demais profundidades em relação

Tabela 1. Parâmetros físicos do Neossolo Quartzarênico, avaliados em duas trincheiras na área irrigada e em duas na área sob sequeiro. Médias de quatro repetições ${ }^{(1)}$.

\begin{tabular}{|c|c|c|c|c|c|c|c|c|c|c|c|c|}
\hline Profundidade (m) & AMG & A G & A M & A F & AMF & A T & Silte & Argila & $\mathrm{Pt}$ & $\mathrm{Ma}$ & $\mathrm{Mi}$ & Ds \\
\hline & 12 & 165 & 215 & 214 & 52 & 880 & 56 & 55 & 02562 & 02230 & 01224 & $\left(\mathrm{t} \mathrm{m}^{-3}\right)$ \\
\hline $0-0,30$ & 12 & 165 & 345 & 314 & 53 & 889 & 56 & 55 & 0,3563 & 0,2339 & 0,1224 & 1,68 \\
\hline $0,30-0,55$ & 8 & 142 & 333 & 314 & 60 & 857 & 55 & 88 & 0,3385 & 0,2068 & 0,1317 & 1,71 \\
\hline $0,55-1,05$ & 9 & 147 & 310 & 289 & 46 & 801 & 79 & 120 & 0,3741 & 0,2228 & 0,1513 & 1,60 \\
\hline $1,05-1,55+$ & 9 & 143 & 314 & 281 & 42 & 789 & 68 & 143 & 0,3545 & 0,2059 & 0,1486 & 1,66 \\
\hline
\end{tabular}

(1)AMG: areia muito grossa; AG: areia grossa; AM: areia média; AF: areia fina; AMF: areia muito fina; AT: areia total; Pt: porosidade total; Ma: macroporos; Mi: microporos; Ds: densidade do solo.

Tabela 2. Relação potencial da água no solo versus umidade, água disponível (AD) e condutividade hidráulica saturada (Ko), em diferentes profundidades do Neossolo Quartzarênico, avaliadas em duas trincheiras na área irrigada e em duas na área sob sequeiro. Médias de quatro repetições.

\begin{tabular}{|c|c|c|c|c|c|c|c|c|}
\hline \multirow{2}{*}{$\begin{array}{l}\text { Profundidade } \\
\text { (m) }\end{array}$} & \multicolumn{6}{|c|}{ Potencial da água no solo (MPa) } & \multirow{2}{*}{$\begin{array}{c}\mathrm{AD} \\
\left(\mathrm{m}^{3} \mathrm{~m}^{-3}\right)\end{array}$} & \multirow{2}{*}{$\begin{array}{c}\mathrm{Ko} \\
\left(\mathrm{mm} \mathrm{h}^{-1}\right)\end{array}$} \\
\hline & 0,001 & 0,01 & 0,03 & 0,10 & 0,30 & 1,50 & & \\
\hline & 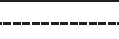 & & ----- U1 & $\mathrm{e}\left(\mathrm{m}^{3} \mathrm{~m}^{-3}\right.$ & & & & \\
\hline $0-0,30$ & 0,2320 & 0,0640 & 0,0544 & 0,0482 & 0,0427 & 0,0372 & 0,0268 & 168,54 \\
\hline $0,30-0,55$ & 0,2184 & 0,0624 & 0,0486 & 0,0422 & 0,0376 & 0,0348 & 0,0276 & 57,32 \\
\hline $0,55-1,05$ & 0,2507 & 0,0746 & 0,0563 & 0,0460 & 0,0419 & 0,0389 & 0,0357 & 141,95 \\
\hline $1,05-1,55+$ & 0,2205 & 0,0779 & 0,0620 & 0,0519 & 0,0467 & 0,0423 & 0,0356 & 93,62 \\
\hline
\end{tabular}

Tabela 3. Parâmetros químicos do Neossolo Quartzarênico, avaliados na linha de plantas (LP) e na entrelinha (EL), em amostras compostas de oito subamostras ${ }^{(1)}$.

\begin{tabular}{|c|c|c|c|c|c|c|c|c|c|c|c|c|}
\hline $\begin{array}{l}\text { Profundidade } \\
(\mathrm{m})\end{array}$ & $\begin{array}{c}\mathrm{pH} \\
\text { (água) }\end{array}$ & $\begin{array}{c}\mathrm{P} \\
\left(\mathrm{mg} \mathrm{dm}^{-3}\right)\end{array}$ & $\mathrm{K}$ & $\mathrm{Ca}$ & $\mathrm{Mg}$ & $\begin{array}{l}\mathrm{Al} \\
\left(\mathrm{cmol}_{\mathrm{c}}\right.\end{array}$ & $\begin{array}{r}\mathrm{Na} \\
\left.\mathrm{dm}^{-3}\right)\end{array}$ & $\mathrm{H}+\mathrm{Al}$ & $\mathrm{S}$ & CTC & $\begin{array}{c}\mathrm{V} \\
(\%)\end{array}$ & $\begin{array}{c}\mathrm{MO} \\
\left(\mathrm{g} \mathrm{kg}^{-1}\right)\end{array}$ \\
\hline $0-0,20 \mathrm{LP}$ & 5,7 & 7 & 0,06 & 1,2 & 0,6 & 0,1 & 0,02 & 1,43 & 1,88 & 3,31 & 57 & 2,50 \\
\hline $0,20-0,40 \mathrm{LP}$ & 5,0 & 3 & 0,04 & 0,6 & 0,4 & 0,2 & 0,02 & 1,65 & 1,06 & 2,71 & 39 & 0,96 \\
\hline $0-0,20 \mathrm{EL}$ & 5,2 & 11 & 0,11 & 0,9 & 0,4 & 0,1 & 0,03 & 1,54 & 1,43 & 2,97 & 48 & 2,02 \\
\hline $0,20-0,40 \mathrm{EL}$ & 4,8 & 8 & 0,09 & 0,3 & 0,3 & 0,4 & 0,03 & 1,87 & 0,72 & 2,59 & 28 & 1,44 \\
\hline
\end{tabular}

(1)V: saturação por bases; MO: matéria orgânica. 
a esse aspecto. Entre os sistemas, comparando-se o total de raízes em cada profundidade, independentemente da posição, houve diferenças apenas na profundidade de $0-0,20 \mathrm{~m}$, que é favorável ao sistema irrigado. Na entrelinha,

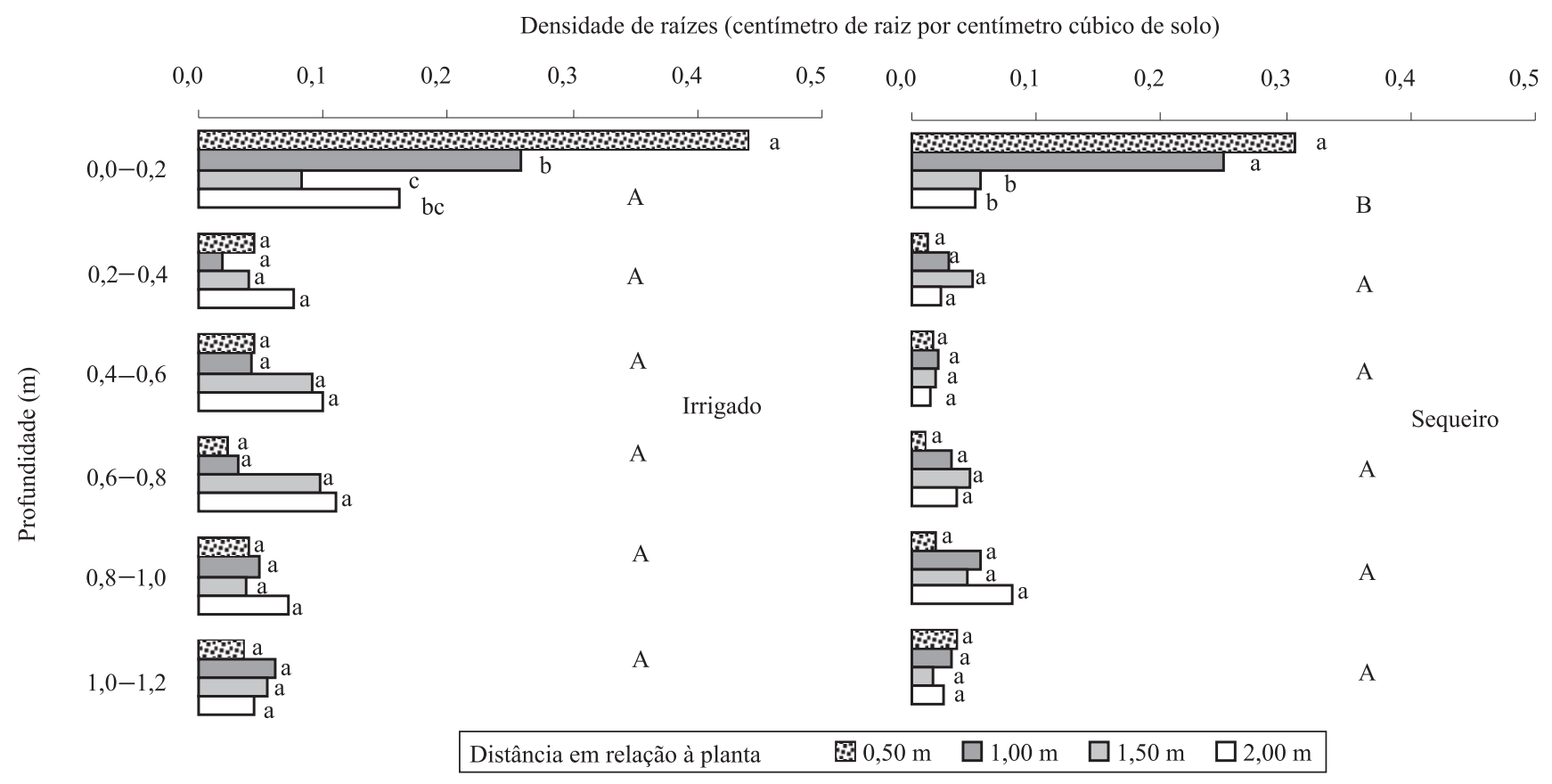

Figura 1. Densidade de raízes das plantas de citros com diâmetro menor do que 0,5 mm (D1), na profundidade 0,0-1,2 m, em diversas distâncias em relação à planta, na linha de plantas (LP), submetidas à irrigação e sequeiro (Tukey 5\% - letras minúsculas: comparam distâncias da planta dentro de cada profundidade; letras maiúsculas: comparam a média de cada profundidade entre irrigado e sequeiro).

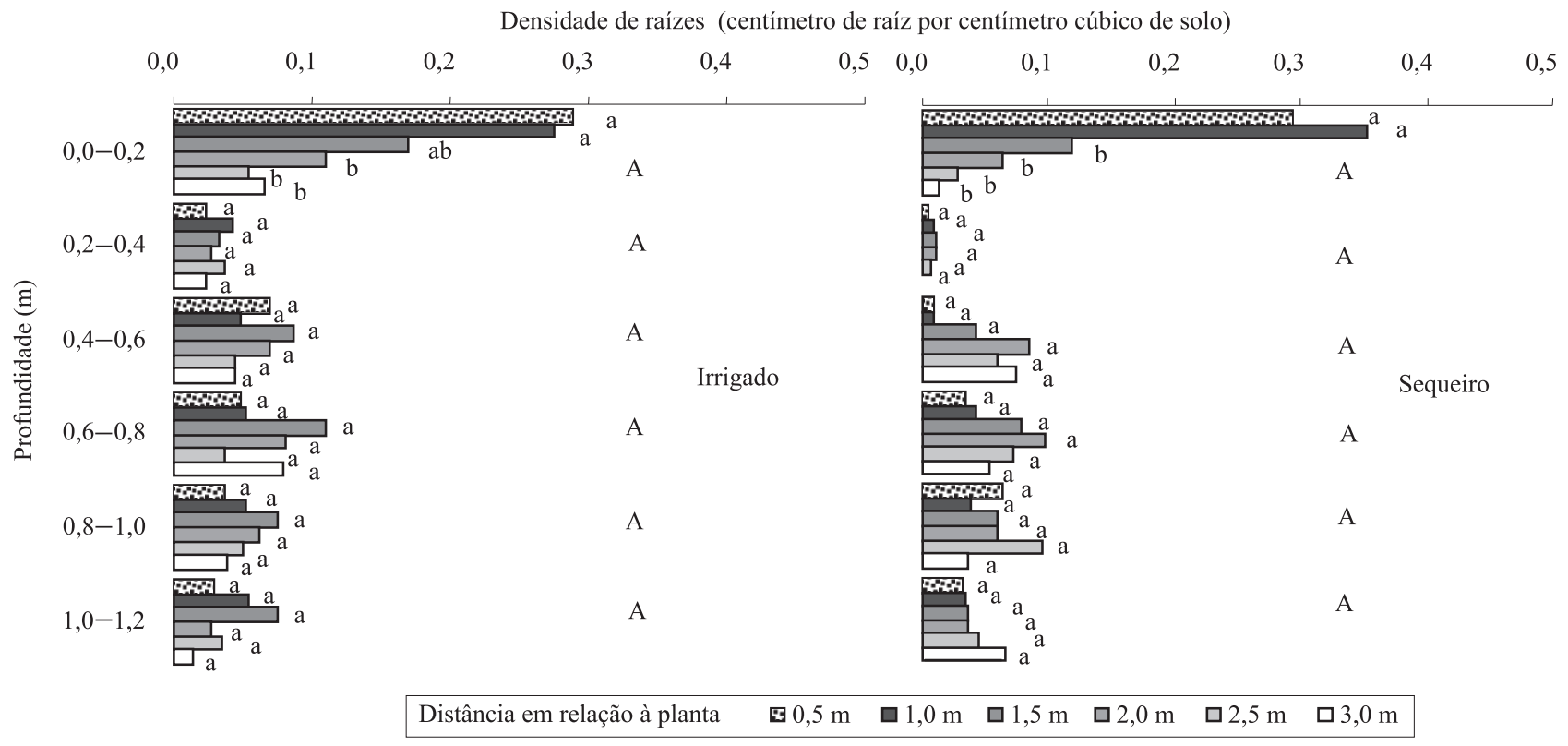

Figura 2. Densidade de raízes das plantas de citros com diâmetro menor do que 0,5 mm (D1), na profundidade de 0,0-1,2 m, em diversas distâncias em relação à planta, na entrelinha (EL), submetidas à irrigação e sequeiro (Tukey $5 \%$ - letras minúsculas: comparam distâncias da planta dentro de cada profundidade; letras maiúsculas: comparam a média de cada profundidade entre irrigado e sequeiro). 
as diferenças dentro de cada sistema também ocorreram somente na camada de $0-0,20 \mathrm{~m}$ (Figura 2). Não houve diferenças entre os dois sistemas, em nenhuma das profundidades, o que demonstra que o sistema de microaspersão utilizado não promoveu o desenvolvimento das raízes mais finas (D1) em profundidade, pois as maiores densidades de raiz, na linha e na entrelinha de plantio, tanto sob irrigação quanto sob sequeiro, estão na profundidade de $0-0,20 \mathrm{~m}$ e até a distância de $1 \mathrm{~m}$ da planta. Ao trabalhar em pomares de citros nos Tabuleiros Costeiros, sob irrigação e sob sequeiro, Coelho et al. (2002) afirmaram que sob irrigação ocorreu maior expansão das raízes mais finas em profundidade, mas, tal afirmação não foi respaldada com testes estatísticos.

Para o diâmetro D2 $(>0,5 \mathrm{e}<1 \mathrm{~mm})$ na linha de plantas (Figura 3) e na entrelinha (Figura 4), ocorreram diferenças entre as posições em relação à planta somente na profundidade de $0-0,20 \mathrm{~m}$, onde ocorreu novamente grande concentração de raízes, nos dois sistemas. $\mathrm{Na}$ linha de plantas, não houve diferenças entre os sistemas irrigado e sequeiro, mas houve diferenças na entrelinha, na profundidade de $0,40-0,60 \mathrm{~m}$, com maior densidade de raízes no sistema irrigado. As Figuras 5 e 6 mostram que o diâmetro D3 ( $>1 \mathrm{~mm}$ ), como os demais, apresentou diferenças nas posições em relação à planta apenas na profundidade de $0-0,20 \mathrm{~m}$, mas não ocorreram diferenças entre os sistemas em nenhuma profundidade, na linha de plantas ou na entrelinha.

As camadas do solo, onde ocorreram as maiores restrições ao desenvolvimento das raízes, estão localizadas no sistema sob sequeiro. $\mathrm{Na}$ entrelinha de plantio, na profundidade $0,20-0,40 \mathrm{~m}$, a distribuição de raízes, em relação ao total no perfil, foi 1,94, 2,97 e 4,19\% para D1, D2 e D3, respectivamente. Na linha de plantas, na profundidade de $0,40-0,60 \mathrm{~m}$, a distribuição foi 5,69, 5,56 e $6,76 \%$ para D1, D2 e D3, respectivamente. Em ambos os casos, o porcentual de raízes foi menor do que na camada sobre e subjacente, o que corrobora as observações de Demattê et al. (1996) e Santana et al. (2006). Deve-se ressaltar que na linha de plantas, no sistema sob sequeiro, a zona de restrição ao desenvolvimento das raízes está em uma profundidade maior do que na entrelinha, efeito que pode ser atribuído ao fato de a linha de plantas ser uma área mais sombreada, sem tráfego de máquinas e revolvimento do solo, comparativamente mais úmida.

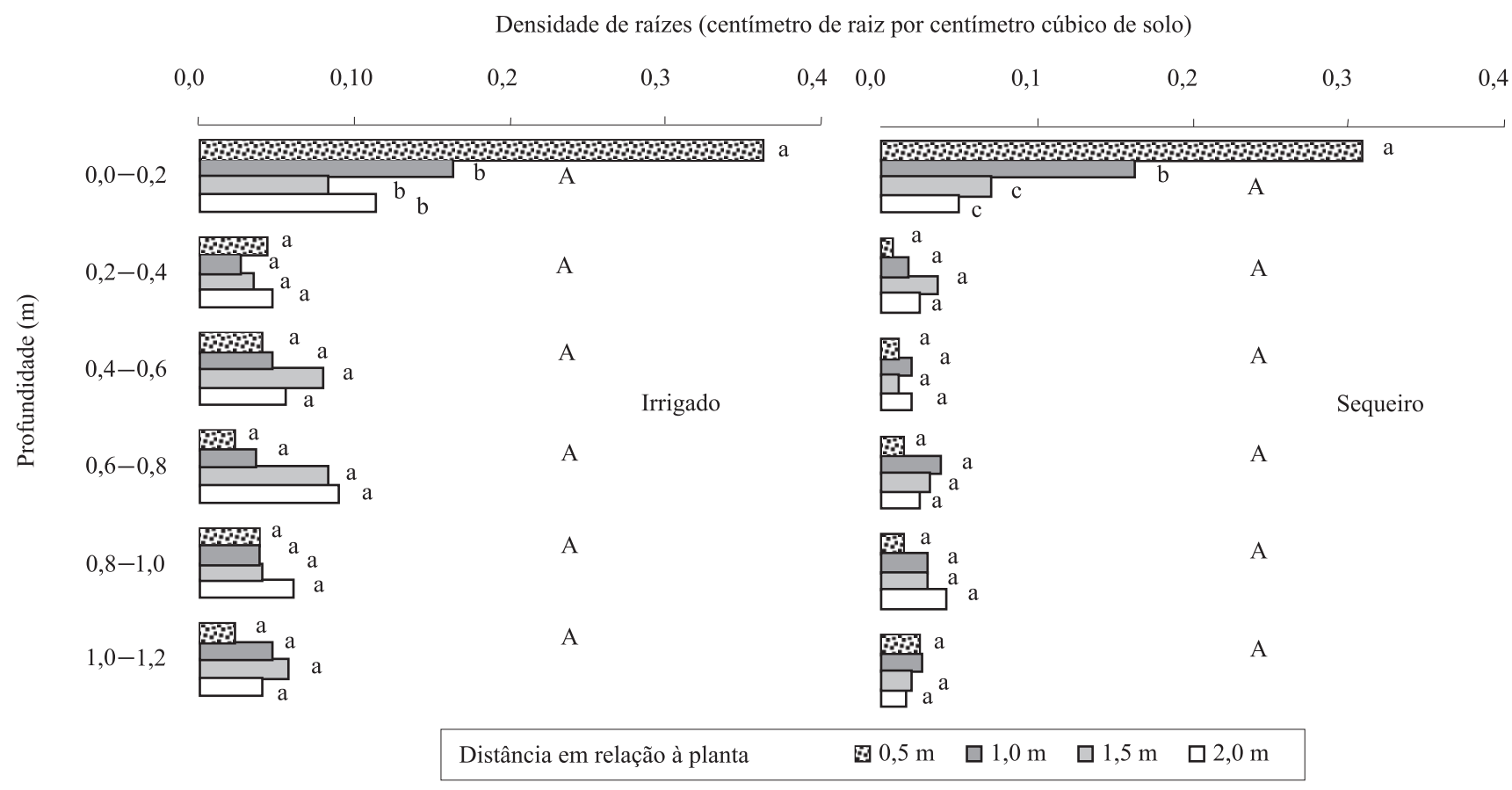

Figura 3. Densidade de raízes das plantas de citros com diâmetro maior do que 0,5 e menor do que 1 mm (D2), na profundidade 0,0-1,2 m, em diversas distâncias em relação à planta, na linha de plantas (LP), submetidas à irrigação e sequeiro (Tukey 5\% letras minúsculas: comparam distâncias da planta dentro de cada profundidade; letras maiúsculas: comparam a média de cada profundidade entre irrigado e sequeiro). 


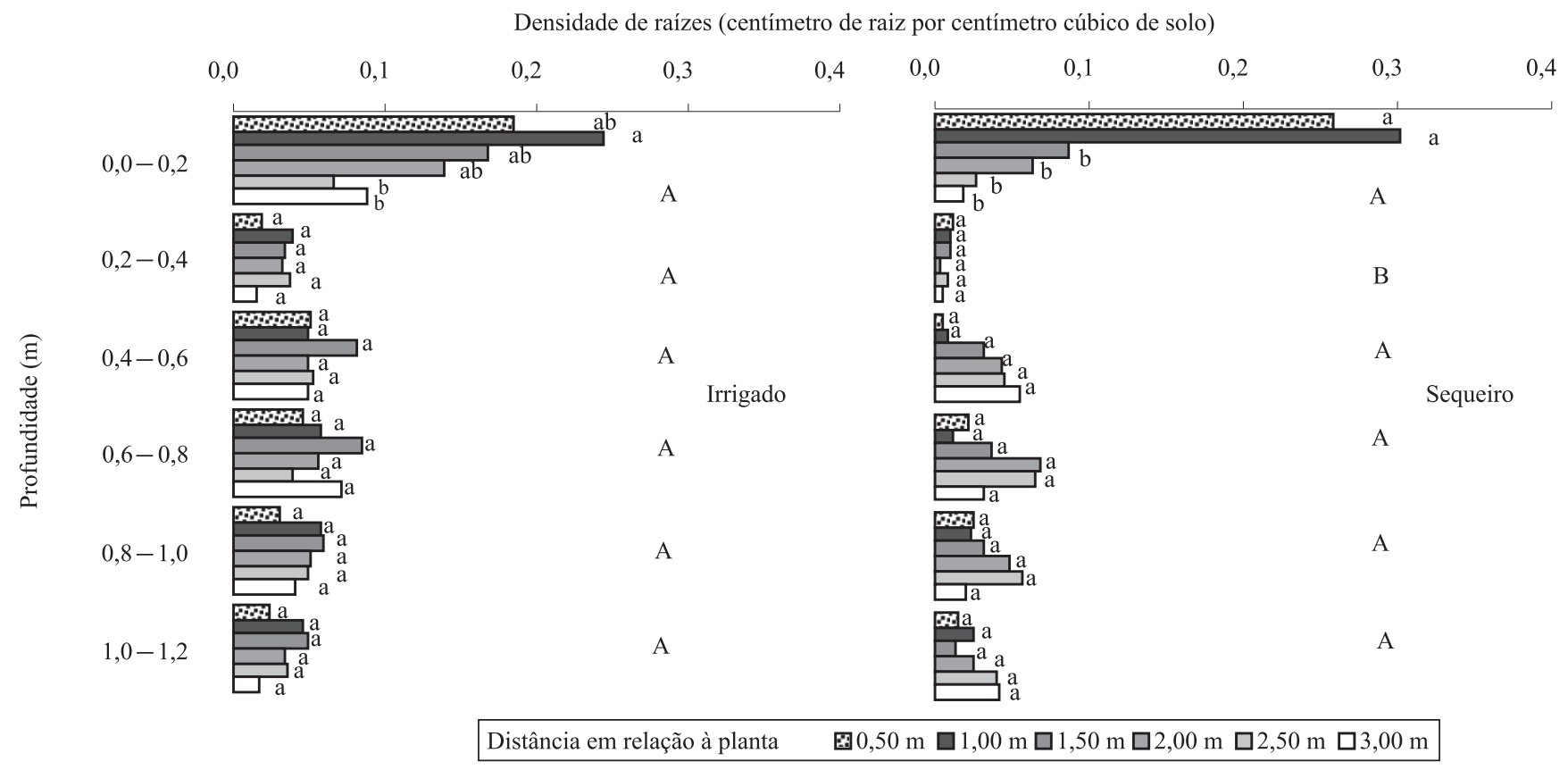

Figura 4. Densidade de raízes das plantas de citros com diâmetro maior do que 0,5 e menor do que 1 mm (D2), na profundidade 0,0-1,2 m, em diversas distâncias em relação à planta, na entrelinha (EL), submetidas à irrigação e sequeiro (Tukey 5\% - letras minúsculas: comparam distâncias da planta dentro de cada profundidade; letras maiúsculas: comparam a média de cada profundidade entre irrigado e sequeiro).

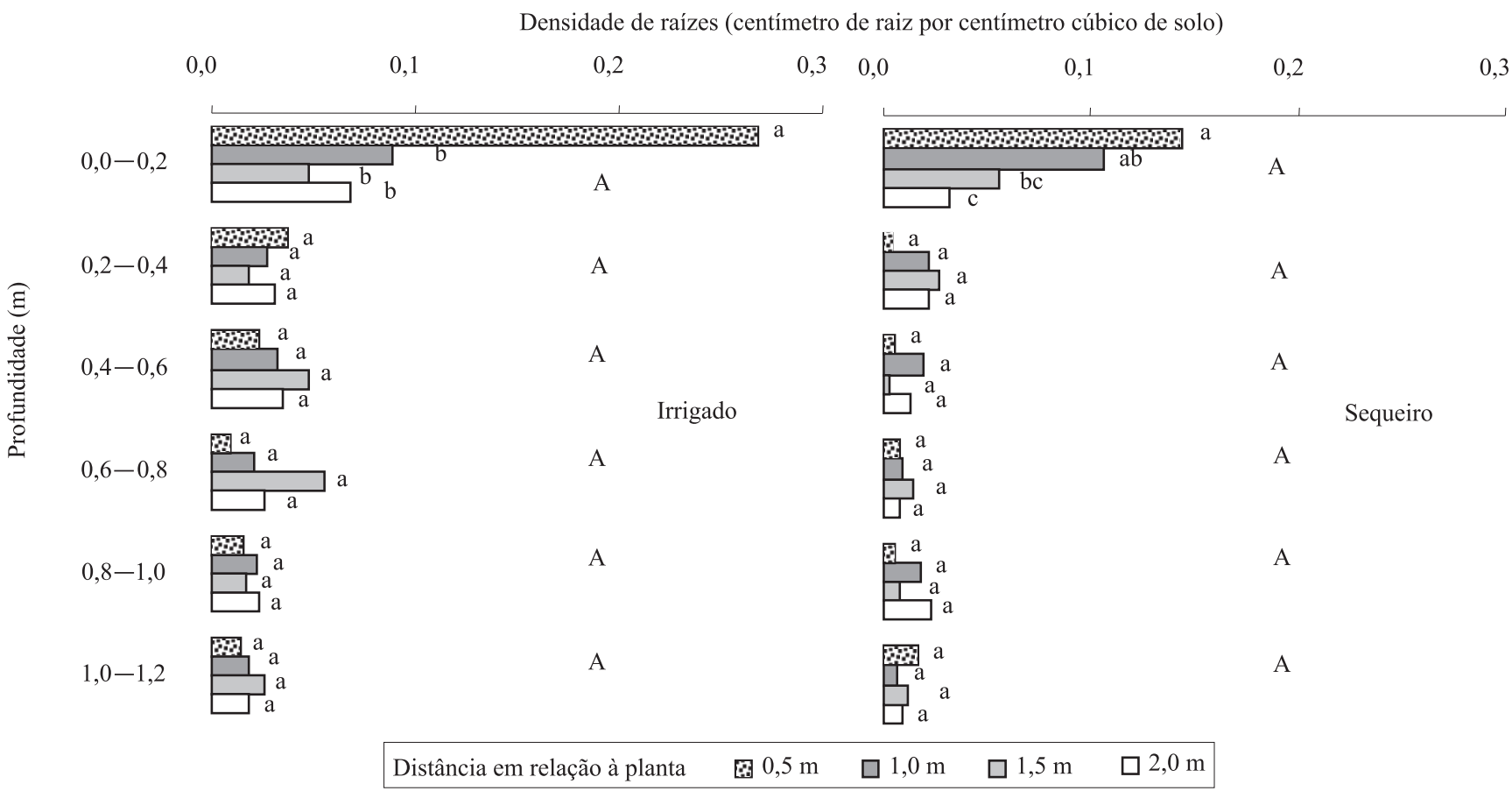

Figura 5. Densidade de raízes das plantas de citros com diâmetro maior do que $1 \mathrm{~mm}$ (D3), na profundidade 0,0-1,2 m, em diversas distâncias em relação à planta, na linha de plantas (LP), submetidas à irrigação e sequeiro (Tukey 5\% - letras minúsculas: comparam distâncias da planta dentro de cada profundidade; letras maiúsculas: comparam a média de cada profundidade entre irrigado e sequeiro). 


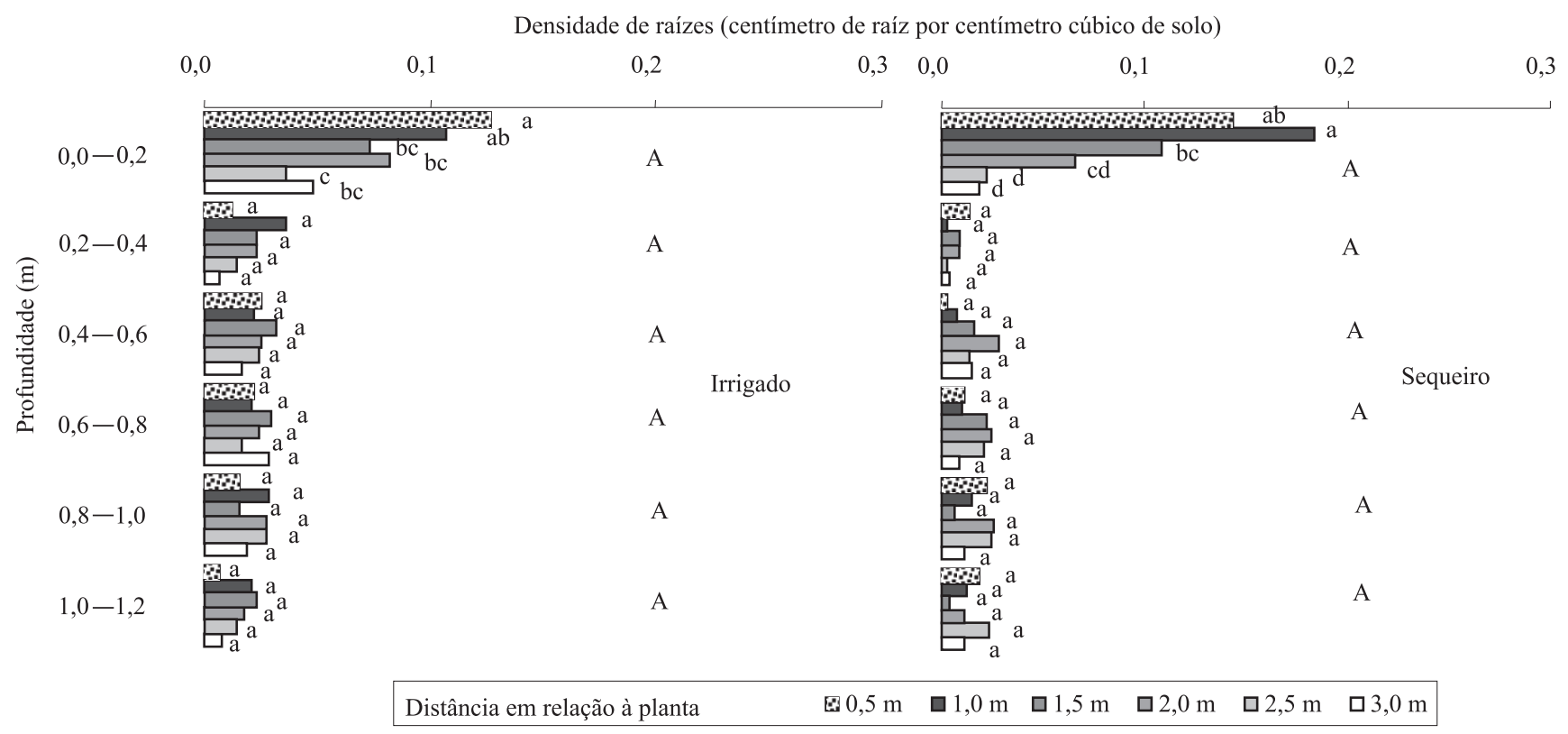

Figura 6. Densidade de raízes das plantas de citros com diâmetro maior do que $1 \mathrm{~mm}$ (D3), na profundidade 0,0-1,2 m, em diversas distâncias em relação à planta, na entrelinha (EL), submetidas à irrigação e sequeiro (Tukey 5\% - letras minúsculas: comparam distâncias da planta dentro de cada profundidade; letras maiúsculas: comparam a média de cada profundidade entre irrigado e sequeiro).

O fato de a camada coesa estar na profundidade de $0,30-0,55 \mathrm{~m}$ deve ser avaliado como um dos fatores para a ocorrência da grande concentração de raízes, na profundidade de $0-0,20 \mathrm{~m}$, para todos os diâmetros de raiz. Na linha de plantas sob irrigação, nessa profundidade, estão $45,70 \%$ do sistema radicular, enquanto sob sequeiro estão $55,49 \%$. Na entrelinha de plantio, encontram-se 40,66 e 48,30\% do total das raízes, para os sistemas sob irrigação e sob sequeiro, respectivamente. A distribuição proporcional das raízes nos diâmetros D1, D2 e D3 foi bastante semelhante para os sistemas irrigado e sequeiro: 43,08, 37,24 e 19,68\%, e $45,38,34,49$ e $20,05 \%$, respectivamente. Os efeitos da irrigação foram mais acentuados na linha de plantas, onde estão instalados os microaspersores, pois nessa posição o sistema sob sequeiro apresentou $61,85 \%$, em relação ao total de raízes sob irrigação, enquanto a entrelinha sob sequeiro apresentou $81,02 \%$ em relação à irrigada. Considerando-se o total de raízes dentro de cada sistema, observou-se que sob irrigação o volume de raízes na linha de plantas foi 17,33\% maior do que na entrelinha, enquanto no sistema sob sequeiro a entrelinha desenvolveu um volume de raízes $8,29 \%$ maior do que a linha de plantas. Em relação à produção de frutos, dados do produtor referentes ao período de 1995 a 2003, no pomar onde foi realizado o experimento, indicaram produtividade de 12 e $21 \mathrm{tha}^{-1}$ por ano, para os sistemas sob sequeiro e irrigado, respectivamente.

\section{Conclusões}

1. O sistema de irrigação por microaspersão não aumenta o volume de solo explorado pelas raízes do limoeiro 'Rugoso' enxertado com laranjeira 'Pêra'.

2. As maiores densidades de raiz, na linha de plantas e entrelinha, encontram-se na profundidade de $0-0,20 \mathrm{~m}$, independentemente do sistema de irrigação e sequeiro, em conseqüência das restrições ao aprofundamento das raízes, impostas pela camada coesa.

3. As menores densidades de raízes no perfil do solo, para todos os diâmetros avaliados, ocorrem no sistema sob sequeiro, na linha de plantas na profundidade de $0,40-0,60 \mathrm{~m}$, e na entrelinha na profundidade de $0,20-0,40 \mathrm{~m}$.

\section{Referências}

ABRAHÃO, W.A.P.; COSTA, L.M.; MELLO, J.W.V.; NEVES, J.C.L. Distribuição de freqüência de tamanho da fração areia e 
compacidade relativa de solos desenvolvidos de sedimentos do Grupo geológico Barreiras. Revista Brasileira de Ciência do Solo, v.22, p.1-9, 1998.

CARVALHO, J.E.B. de; SOUZA, L. da S.; JORGE, L.A. de C.; RAMOS, W.F.; COSTA NETO A. de O.; ARAÚJO, A.M. de A.; LOPES, L.C.; JESUS, M.S. de. Manejo de coberturas do solo e sua interferência no desenvolvimento do sistema radicular da laranja 'Pêra'. Revista Brasileira de Fruticultura, v.21, p.140-145, 1999.

CINTRA, F.L.D.; LIBARDI, P.L.; JORGE, L.A. de C. Distribuição do sistema radicular de porta-enxertos de citros em ecossistema de Tabuleiro Costeiro. Revista Brasileira de Fruticultura, v.21, p.313-317, 1999.

COElHO, E.F.; OLIVEIRA, F. das C.; ARAÚJO, E.C.E.; VASCONCELOS, L.F.L. Distribuição das raízes de laranja 'Pêra' sob sequeiro e irrigação por microaspersão em solo arenoso. Pesquisa Agropecuária Brasileira, v.37, p.603-611, 2002.

COELHO, Y. da S.; MAGALHÃES, A.F. de J.; CINTRA, F.L.D. Levantamento nutricional de pomares cítricos na Bahia: II. Características químicas e físicas dos solos. Revista Brasileira de Fruticultura, v.15, p.67-73, 1993.

DEMATTÊ, J.L.I.; MAZZA, J.A.; DEMATTÊ, J.A.M. Caracterização e gênese de uma toposseqüência Latossolo AmareloPodzol originado de material da formação Barreiras, Estado de Alagoas. Scientia Agricola, v.53, p.20-30, 1996.

EMBRAPA. Centro Nacional de Pesquisa de Solos. Manual de métodos de análise de solo. Rio de Janeiro: Embrapa-CNPS, 1997. 212 p.

EMBRAPA. Centro Nacional de Pesquisa de Solos. Sistema brasileiro de classificação de solos. Brasília: Embrapa-SPI; Rio de Janeiro: Embrapa-CNPS, 1999. 412p.

GIAROLA, N.F.B.; SILVA, A.P. da; SOUZA, L. da S.; RIBEIRO, L.P. Similaridades entre o caráter coeso dos solos e o comportamento 'hardsetting': estudo de caso. Revista Brasileira de Ciência do Solo, v.25, p.239-247, 2001.

GRUPO PAULISTA DE ADUBAÇÃO E CALAGEM PARA CITROS. Recomendações de adubação e calagem para citros no Estado de São Paulo. Laranja, v.15, p.1-27, 1994.

GUDDANTI, S.; CHAMBERS, J.L. GSRoot: automated root length measurement program, user's manual. Louisiana: Louisiana State University, 1993. 40p. (Version 5.00).

IBGE. Valor da produção agrícola municipal. Rio de Janeiro: IBGE-SIDRA. Disponível em: http://www.ibge.gov.br. Acesso em: 7 jan. 2007.

JACOMINE, P.K.T. Evolução do conhecimento sobre solos coesos no Brasil. In: WORKSHOP COESÃO EM SOLOS DOS TABULEIROS COSTEIROS, Aracaju, 2001. Anais. Aracaju: Embrapa Tabuleiros Costeiros, 2001. p.19-46.

JACOMINE, P.K.T.; CAVALCANTI, A.C.; SILVA, F.B.R. e; MONTENEGRO, J.O.; FORMIGA, R.A.; BURGOS, N.; MELO
FILHO, H.F. de. Levantamento exploratório: reconhecimento de solos da margem direita do Rio São Francisco, Estado da Bahia. Recife: Embrapa-SNLCS, 1977. 735p. (Boletim Técnico, 52).

LIMA, H.V.; SILVA, A.P.; JACOMINE, P.T.K.; ROMERO, R.E.; LIBARDI, P.L. Identificação e caracterização de solos coesos no Estado do Ceará. Revista Brasileira de Ciência do Solo, v.28, p.467-476, 2004.

NEVES, C.S.V.J.; MURATA, I.M.; STENZEL, N.M.C.; MEDINA, C. de C.; BORGES, A.V.; OKUMOTO, S.H.; LEE, R.H.; KANAI, H.T. Root distribution of rootstocks for 'Tahiti' lime. Scientia Agricola, v.6, p.94-99, 2004.

PAIVA, A.Q.; SOUZA, L.S.; RIBEIRO, A.C.; COSTA, L.M. Disponibilidade de água de uma topossequiência de solos de tabuleiro do Estado da Bahia e sua relação com os indicadores do crescimento da laranjeira. Revista Brasileira de Ciência do Solo, v.22, p.367$377,1998$.

PORTELA, J.C.; LIBARDI, P.L.; LIER, Q. de J. van. Retenção da água em solo sob diferentes usos no ecossistema Tabuleiro Costeiro. Revista Brasileira de Engenharia Agrícola e Ambiental, v.5, p.49-54, 2001.

RESENDE, M.; CARVALHO FILHO, A.; LANI, J.L. Características do solo e da paisagem que influenciam a susceptibilidade à erosão. In: SIMPÓSIO SOBRE MANEJO E CONSERVAÇÃO DO SOLO NO CERRADO, 1., Campinas, 1992. Anais. Campinas: Fundação Cargill, 1992. p.32-67.

REZENDE, J. de O.; MAGALHÃES, A.F. de J.; SHIBATA, R.T.; ROCHA, E.S.; FERNANDES, J.C.; BRANDÃO, F.J.C.; REZENDE, V.J.R.P. Citricultura nos solos coesos dos Tabuleiros Costeiros: análise e sugestões. Salvador: SEAGRI-SPA, 2002.97p. (Série Estudos Agrícolas, 3).

SANTANA, M.B.; SOUZA, L. da S.; SOUZA, L.D.; FONTES, L.E.F. Atributos físicos do solo e distribuição do sistema radicular de citros como indicadores de horizontes coesos em dois solos de Tabuleiros Costeiros do Estado da Bahia. Revista Brasileira de Ciência do Solo, v.30, p.1-12, 2006.

SAS INSTITUTE. Statistical analysis system: user's guide. Cary: SAS Institute, 1999. (Versão 8.2).

SOUZA, L. da S.; PAIVA, A. de Q. Variação do potencial total da água em uma topossequiência de solos de tabuleiro, durante dois anos. Pesquisa Agropecuária Brasileira, v.36, p.349-355, 2001.

SOUZA, L.D.; CUNHA SOBRINHO, A.P. da; RIBEIRO, L. da S.; SOUZA, L. da S.; LEDO, C.A. da S. Avaliação de plantas cítricas, em diferentes profundidades de plantio, em Latossolo Amarelo dos Tabuleiros Costeiros. Revista Brasileira de Fruticultura, v.26, p.241-244, 2004b.

SOUZA, L.D.; SOUZA, L. da S.; LEDO, C.A. da S. Disponibilidade de água em pomar de citros submetido à poda e subsolagem em Latossolo Amarelo dos Tabuleiros Costeiros. Revista Brasileira de Fruticultura, v.26, p.69-73, 2004a.

Recebido em 1o de junho de 2007 e aprovado em 10 de setembro de 2007 